JAMA Oncology | Review

\title{
Safety, Tolerability, and Management of Toxic Effects of Phosphatidylinositol 3-Kinase Inhibitor Treatment in Patients With Cancer
}

\section{A Review}

Angela Esposito, MD; Giulia Viale, MD; Giuseppe Curigliano, MD, PhD

IMPORTANCE The phosphatidylinositol 3-kinase (PI3K)/protein kinase B (AKT)/mammalian target of rapamycin (mTOR) signaling pathway, which regulates multiple cellular processes, including metabolism, proliferation, motility, growth, and survival, is one of the most frequently dysregulated pathways in human cancers. The PI3K/AKT/mTOR cascade can be aberrantly activated by multiple factors, including diverse oncogenic genomic alterations in PIK3CA, PIK3R1, PTEN, AKT, TSC1, TSC2, LKB1, MTOR, and other critical genes, which can be used as targets for anticancer therapy. Limited single-agent activity, high levels of toxic effects, and a lack of predictive biomarkers for treatment selection have all been major barriers to the clinical development of these compounds. Many adverse effects are uncommon and have poorly understood mechanisms. An understanding of these toxic effects, as well as a better definition of management guidelines, will be important because more PI3K inhibitors are under development and may soon be incorporated into routine practice.

OBSERVATIONS A search of PubMed, draft prescribing information of currently approved PI3K inhibitors, European Medical Association and US Food and Drug Administration product information, and expert panel opinion on the management of the prominent toxic effects of this class of agents was conducted on August 29, 2018. This article provides an overview of the main toxic effects of PI3K inhibitors reported in clinical trials and a summary of recommendations for identification and management of treatment-emergent toxic effects, in-l. Iding hypoglycemia, cutaneous reactions, pneumonitis, neuropsychiatric effects, han totoxic effects, diarrhea, and colitis. Overall, the clinical development of most PI3K in hitors has been discontinued owing to insufficient activity, problematic toxic effects, and the absence of biomarkers correlated with clinical activity. Knowledge of the isoforms and their distribution in tissue can help clinicians anticipate toxic effects. Notably, novel, more specific inhibitors for individual isoforms of PI3K showed therapeutic activity with improved toxic effect profiles compared with non-isoform-selective agents.

CONCLUSIONS AND RELEVANCE An improved understanding of the complexities of the main toxic-effect mechanisms and their management might open viable paths to advancing PI3K inhibitors from clinical studies to new standard-of-care treatments.
Author Affiliations: Division of Early Drug Development for Innovative Therapies, IEO, European Institute of Oncology, IRCCS Milano, Milan, Italy (Esposito, Curigliano); Department of Oncology and Hemato-Oncology, University of Milan, Milan, Italy (Viale, Curigliano).

Corresponding Author: Giuseppe Curigliano, MD, PhD, European Institute of Oncology, IRCCS Milano, Via Ripamonti 435, 20141, Italy (giuseppe.curigliano@ieo.it). 
$\mathrm{T}$ he phosphatidylinositol 3-kinase (PI3K)/protein kinase B (AKT)/mammalian target of rapamycin (mTOR) pathway plays a major role in the survival, growth, and dissemination of several tumors. It is one of the most frequently dysregulated signaling pathways in tumors and can be aberrantly activated through different mechanisms. ${ }^{1}$ Preclinical and clinical evidence supported the rationale of targeting the PI3K/AKT/mTOR pathway, leading to the development of several PI3K and AKT inhibitors, as well as allosteric mTOR and catalytic mTOR kinase inhibitors. However, because PI3K is the most proximal component of the pathway, targeting $\mathrm{PI} 3 \mathrm{~K}$ itself rather than AKT or mTOR may induce a pronounced inhibition of the downstream components within the pathway and reverse eventual resistance to previous therapies. ${ }^{2-5}$

The PI3K family is divided into 3 classes (I, II, and III) that differ in coding genes, structures, and substrate preference. ${ }^{6}$ The different $\mathrm{PI} 3 \mathrm{~K}$ isoforms have diverse tissue distribution that informs their expected activity and toxic effect profile (Table 1). The PI3K $a$ and $\beta$ isoforms are expressed almost ubiquitously and regulate a wide range of physiological processes, including cell growth, proliferation, differentiation, motility, survival, and intracellular trafficking; PI3Ka plays also a key role in glucose homeostasis. The $y$ and $\delta$ isoforms are preferentially expressed on leukocytes ${ }^{21,22}$ and control different aspects of immune responses. The effects of PI3K inhibition on different lymphocyte subsets are classically involved in the development of autoimmune toxic effects. ${ }^{23}$ Because of their immunomodulatory role, recent preclinical studies supported the rationale of combining PI3K $\delta$ isoform inhibitors, such as copanlisib dihydrochloride, with immune checkpoint blockers. ${ }^{24}$ Moreover, PI3K $ү$ is involved in blood pressure homeostasis by regulating particularly myogenic tone. Pan-PI3K inhibitors block the catalytic activity of all $4 \mathrm{PI} 3 \mathrm{~K}$ class I isoforms (p110a, p110, p110y, and p110ס), ${ }^{7}$ as shown in the Figure. Pan-PI3K inhibitors in current development include copanlisib, buparlisib hydrochloride, and SF1126. Overall, the clinical development of most pan-PI3K inhibitors, such as pictilisib, pilaralisib, and PX-866, has been interrupted owing to the high frequency of toxic effects and modest antitumor activity. ${ }^{1}$ Dual inhibitors of PI3K and mTORC1/2, including gedatolisib and LY3023414, result in the blockade of the 3 most critical nodes of the PI3K/AKT/mTOR pathway, with a toxic effect profile similar to pan-PI3K inhibitors. Isoformspecific PI3K inhibitors are supposed to have a more favorable safety profile owing to fewer off-target adverse events and a wider therapeutic index. In this class of drugs, the only approved agent is idelalisib, a selective PI3K $\delta$ inhibitor. According to their preferential distribution and activity, in addition to shared adverse effects (eg, fatigue, nausea, vomiting, and diarrhea), inhibition of the PI3Ka isoform may be associated with hyperglycemia; inhibition of PI3K $\beta$ isoform, with anemia; inhibition of PI3Ky, with hypertension; and blockade of PI $3 \mathrm{~K} \delta$, with immunomodulation, leading to skin eruption, liver dysfunction, pneumonitis, pyrexia, and hematologic toxic effects. ${ }^{8}$ The PI3K/AKT/mTOR pathway is frequently dysregulated in tumors, and alterations of this signaling pathway have been associated with resistance to anticancer therapies. Thus, PI3K inhibitors have been tested in hematologic tumors as well as in breast cancer, either hormone receptor-positive or HER2-positive breast cancer; head and neck squamous cell carcinoma; non-small cell lung carcinoma; and glioblastoma multiforme. Across these studies, PI3K inhibitors showed generally modest activity as monotherapy; however, promising results have been obtained with $\mathrm{PI} 3 \mathrm{~K}$ in combination with other standard treatment. For example, in the recently presented Study Assessing the Efficacy and Safety of Alpelisib Plus Fulvestrant in Men and Postmenopausal Women With Advanced Breast Cancer Which Progressed on or After Aromatase Inhibitor Treatment (SOLAR-1) trial, alpelisib plus fulvestrant was shown to provide a progression-free survival benefit in patients with hormone receptor-positive, HER2-negative advanced breast cancer with PIK3CA mutations detected in tumor tissue. ${ }^{9}$ On the other hand, the phase 3 Study of Taselisib + Fulvestrant vs Placebo + Fulvestrant in Participants With Advanced or Metastatic Breast Cancer Who Have Disease Recurrence or Progression During or After Aromatase Inhibitor Therapy (SANDPIPER) trial tested taselisib in combination with fulvestrant and showed a modest 2-month benefit in median progression-free survival for the combination arm in patients with es-

Table 1. Frequency of Common Toxic Effects Associated With Phosphatidylinositol 3-Kinase (PI3K) Inhibitors in Clinical Trials ${ }^{\mathrm{a}}$

\begin{tabular}{|c|c|c|c|c|}
\hline Toxic Effect & Alpelisib & Idelalisib & Copanlisib & Buparlisib \\
\hline PI3K isoform specificity & PI3Ka inhibitor & PIЗKס inhibitor & $\mathrm{PI} 3 \mathrm{Ka}, \delta$ inhibitor & Pan-PI3K inhibitor \\
\hline Hyperglycemia, \% & $\begin{array}{l}\text { All grades, } 51 \%^{7} \text {; all grades, } \\
62 \%^{8} \text {; all grades, } 59 \%^{9} \\
\text { grade }>3: 26 \%^{7}\end{array}$ & NR & $\begin{array}{l}\text { All grades: } 57 \%^{10} \text {; grade }>3 \text { : } \\
41 \%^{11}\end{array}$ & All grades: $12 \%^{12}$; all grades $58 \%^{13}$ \\
\hline Cutaneous reactions & All grades: $42 \%^{7}(11)$ & All grades: $21 \%{ }^{14}$ & $\begin{array}{l}\text { Grade } 3: 2.8 \%^{11} \text {; grade } 4 \text { : } \\
0.6 \%^{11}\end{array}$ & All grades: $30 \%{ }^{15}$ \\
\hline Hypertension & NR & NR & $\begin{array}{l}\text { All grades } 30 \%^{16} ; \text { all grades } \\
54.8 \%^{10} ; \text { grade }>3: 24 \%{ }^{16,17} \\
\text { grade }>3: 40.5 \%{ }^{10}\end{array}$ & NR \\
\hline Pneumonitis & NR & All grades: $25 \%{ }^{17}$ & $\begin{array}{l}\text { All grades } 5 \%^{11} ; \text { grade }>3 \text { : } \\
15 \%^{17}\end{array}$ & NR \\
\hline Neuropsychiatric effects & NR & NR & NR & $\begin{array}{l}\text { Confusion grade }>3 \text { : } 10 \%^{18} \text {; suicidal } \\
\text { ideation: } 2 \%^{12} \text {; depression: } 3.3 \%^{19} \text {; } \\
\text { anxiety: } 3.9 \%^{19}\end{array}$ \\
\hline Hepatotoxic effects & NR & $\begin{array}{l}\text { Grade }>3: 14 \%^{17} ; \text { all } \\
\text { grades: } 41 \%-50 \%{ }^{17}\end{array}$ & NR & Grade $>3: 25 \%^{20} ;$ grade $>3: 20 \%^{12}$ \\
\hline Diarrhea & All grades: $46 \%^{7}$ & Grade $>3: 14 \%-19 \%^{17}$ & NR & NR \\
\hline $\begin{array}{l}\text { Abbreviations: CTCAE, Cor } \\
\text { not reported or reported fi } \\
\text { a The grades listed are CTC } \\
\text { Grade 1, mild: asymptom } \\
\text { observations only; interv }\end{array}$ & $\begin{array}{l}\text { erminology Criteria for Advers } \\
\text { cy rate less than } 1 \% \text {. } \\
\text { les, for which the toxic effects } \\
\text { nild symptoms; clinical or diagr } \\
\text { not indicated. Grade 2, modera }\end{array}$ & $\begin{array}{l}\text { Events; NR, } \\
\text { ostic as follows: } \\
\text { e: minimal, }\end{array}$ & \multicolumn{2}{|c|}{$\begin{array}{l}\text { local or noninvasive intervention indicated; limiting age-appropriate } \\
\text { instrumental ADL. Grade 3, severe or medically significant but not immediately } \\
\text { life-threatening: hospitalization or prolongation of hospitalization indicated, } \\
\text { disabling, or limiting self-care ADL. Grade 4, life-threatening consequences: } \\
\text { urgent intervention indicated. }\end{array}$} \\
\hline
\end{tabular}


Figure. Overview of Phosphatidylinositol 3-Kinase/Mammalian Target of Rapamycin (PI3K/mTOR) Pathway and of PI3K Inhibitors Approved or in Phase 2 or 3 of Clinical Development

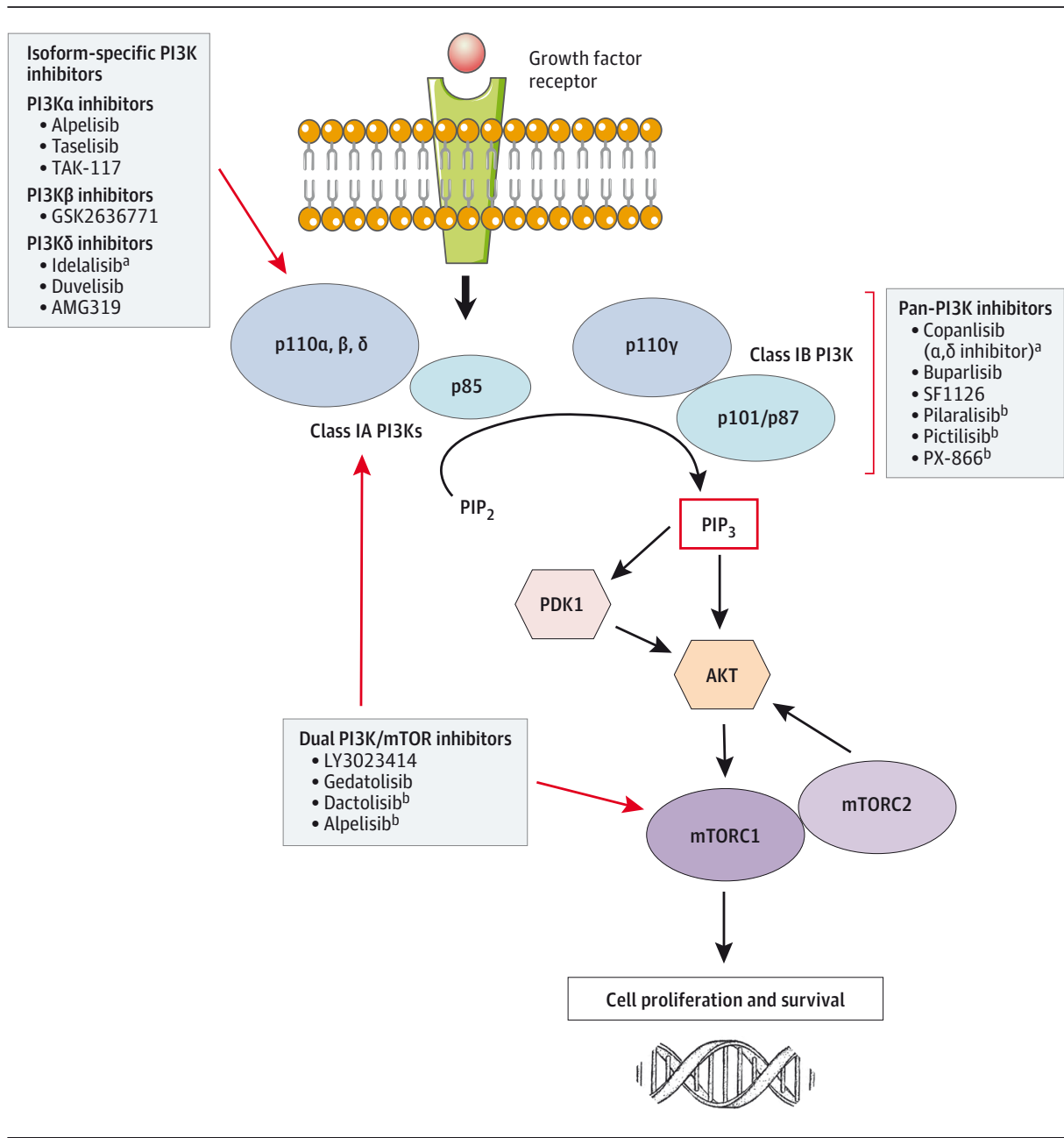

The PI3Ks constitute a lipid kinase family that is involved in different physiological processes. These enzymes, through the formation of the second messenger phosphatidylinositol $(3,4,5)$-trisphosphate $\left(\mathrm{PIP}_{3}\right)$, induce the activation of downstream protein kinases, most notably phosphoinositide-dependent kinase 1 (PDK1), and ultimately of other proteins, such as mTOR, $B C L 2$-associated agonist of cell death (BAD), and forkhead box 0 proteins. The PI3K family is divided into 3 classes (I, II, and III) that differ for coding genes, structures, and substrate preference. Class I isoforms are further divided according to their subunits into 2 classes: class IA composed of a catalytic subunit (p110 with 3 isoforms: p110a, p110 $\beta$, and p110ס), and a regulatory subunit (p85) and class IB (p110y), which binds to $\mathrm{p} 87$ and p101. Pan-PI3K inhibitors block, to some degree, the catalytic activity of all 4 PI3K class I isoforms (p110a, p110, p110y, and p110ठ). The only approved agents are idelalisib, a selective PI3K $\delta$ inhibitor, and copanlisib dihydrochloride, an inhibitor of PI3Ka as well as PI3K isoforms. AKT indicates protein kinase $\mathrm{B} ; \mathrm{PIP}_{2}$, phosphatidylinositol bisphosphate.

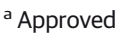

${ }^{\mathrm{b}}$ No further development. trogen receptor-positive, PIK3CA-mutant locally advanced or metastatic breast cancer at the cost of more severe serious adverse effects, notably gastrointestinal toxic effects. ${ }^{10}$

\section{Methods}

On August 29, 2018, we searched PubMed, draft-prescribing information of currently approved PI3K inhibitors, European Medical Association and US Food and Drug Administration (FDA) product information, and expert panel opinion on the management of the most common toxic effects of this class of agents. The search terms used were combinations of PI3K inhibitors, toxic effects, management, product information. We reviewed published clinical trials, focusing on the incidence and management of the main toxic effects related to PI3K inhibitors.

\section{Management of the Most Relevant Toxic Effects}

Although guidelines have been established for idelalisib and copanlisib, formal guidelines for the identification and management of ad- ditional toxic effects associated with PI3K inhibitors have yet to be generated and made available to treating physicians. Below, we propose a potential algorithm for the management of some particular toxic effects associated with the use of PI3K inhibitors ${ }^{14,17,25,26}$ (Table 2).

\section{Hyperglycemia}

Hyperglycemia typically occurs within the first month of treatment, and it is mainly expected as an adverse event associated with the inhibition of the PI3Ka subunit, which has a key role in insulin signaling and glucose homeostasis. In a phase 2 clinical trial with alpelisib, hyperglycemia of all grades was described in 69 of 134 patients (51.5\%), being the most frequent grades 3 and 4 treatmentrelated adverse event and dose-limiting toxic effects. ${ }^{12}$ Twenty-six of 43 patients $(60.4 \%)$ treated with alpelisib in combination experienced mild to moderate hyperglycemia; 16 of 26 (61.5\%) receiving alpelisib and letrozole; and 10 of 17 (58.8\%) receiving alpelisib plus TDM1. ${ }^{13,27}$ In a phase 2 trial investigating copanlisib for hematologic cancers, the incidence of hyperglycemia as a treatmentrelated adverse event was $57.1 \%$, with a severity of grade 3 or greater in $23.8 \%$ of the patients who experienced hyperglycemia. ${ }^{11} \mathrm{Simi}$ larly, the phase 2 Open-Label, Uncontrolled Phase II Trial of Intra- 


\begin{tabular}{|c|c|c|c|c|c|}
\hline $\begin{array}{l}\text { CTCAE Grade of } \\
\text { Toxic Effects }^{\mathrm{b}}\end{array}$ & Hyperglycemia & Cutaneous Reactions & Hypertension & Diarrhea & Neuropsychiatric Symptoms \\
\hline Grade 1 & $\begin{array}{l}\text { Maintain drug and counsel } \\
\text { patient on lifestyle } \\
\text { changes; consider adding } \\
\text { metformin hydrochloride } \\
\text { in cooperation with } \\
\text { diabetologist }\end{array}$ & $\begin{array}{l}\text { Maintain drug } \\
\text { treatment; initiate } \\
\text { topical corticosteroid } \\
\text { therapy; for patients } \\
\text { with symptoms, such as } \\
\text { burning or pruritus, add } \\
\text { antihistamine to therapy }\end{array}$ & $\begin{array}{l}\text { Maintain drug treatment } \\
\text { and follow up; medical } \\
\text { intervention not indicated }\end{array}$ & $\begin{array}{l}\text { Maintain drug } \\
\text { treatment; } \\
\text { antidiarrheal } \\
\text { medication } \\
\text { recommended at first } \\
\text { sign of abdominal } \\
\text { cramping, loose stools, } \\
\text { or overt diarrhea }\end{array}$ & $\begin{array}{l}\text { Monitor closely; consider } \\
\text { psychiatric referral }\end{array}$ \\
\hline Grade 2 & $\begin{array}{l}\text { Maintain drug and counsel } \\
\text { patient of lifestyle } \\
\text { changes; start oral } \\
\text { antidiabetic treatment; if } \\
\text { FPG level is still increasing } \\
\text { with maximum tolerated } \\
\text { dose of metformin or } \\
\text { persistently }>160 \mathrm{mg} / \mathrm{dL} \text {, } \\
\text { add an insulin-sensitizer } \\
\text { (eg, pioglitazone, } 30 \mathrm{mg} \text { ) }\end{array}$ & $\begin{array}{l}\text { Maintain drug } \\
\text { treatment; initiate } \\
\text { topical corticosteroid } \\
\text { therapy; for patients } \\
\text { with symptoms, such as } \\
\text { burning or pruritus, add } \\
\text { antihistamine to } \\
\text { therapy; consider adding } \\
\text { systemic corticosteroids } \\
\text { to therapy }\end{array}$ & $\begin{array}{l}\text { Maintain drug treatment } \\
\text { and start antihypertensive } \\
\text { treatment }\end{array}$ & $\begin{array}{l}\text { Stop drug treatment } \\
\text { until resolved } \\
\text { to } \leq \text { grade } 1\end{array}$ & $\begin{array}{l}\text { Stop drug treatment and order } \\
\text { evaluation by psychiatrist } \\
\text { before restarting drug } \\
\text { treatment; consider initiating } \\
\text { appropriate psychiatric therapy, } \\
\text { such as a selective serotonin } \\
\text { reuptake inhibitor or serotonin } \\
\text { and norepinephrine reuptake } \\
\text { inhibitor }\end{array}$ \\
\hline Grade 3 & $\begin{array}{l}\text { Stop drug treatment until } \\
\text { resolved to } \leq \text { grade } 1 \text {; } \\
\text { treat electrolyte } \\
\text { disturbances as clinically } \\
\text { appropriate; start } \\
\text { metformin therapy and } \\
\text { titrate as outlined for } \\
\text { grade } 2 \text {, add pioglitazone } \\
\text { as outlined for grade } 2 \text {; } \\
\text { insulin may be used for } 1-2 \\
\text { d until hyperglycemia } \\
\text { resolves; if FPG level } \\
\text { resolves to } \leq \text { grade } 1 \text {, } \\
\text { consider reducing drug } \\
\text { dosage }\end{array}$ & $\begin{array}{l}\text { Stop drug treatment } \\
\text { until skin eruption or } \\
\text { toxic effect is no longer } \\
\text { active but fading (grade } \\
\text { 1); initiate topical and } \\
\text { systemic corticosteroid } \\
\text { therapy; for patients } \\
\text { with symptoms, such as } \\
\text { burning or pruritus, add } \\
\text { antihistamine to therapy }\end{array}$ & $\begin{array}{l}\text { Stop drug treatment and } \\
\text { consider inpatient } \\
\text { management }\end{array}$ & $\begin{array}{l}\text { Stop drug treatment } \\
\text { until resolved } \\
\text { to } \leq \text { grade } 1 \text {, then } \\
\text { consider restarting } \\
\text { treatment at reduced } \\
\text { dosage }\end{array}$ & $\begin{array}{l}\text { Withhold drug treatment and } \\
\text { admit patient to hospital for } \\
\text { psychiatric evaluation }\end{array}$ \\
\hline Grade 4 & $\begin{array}{l}\text { Permanently stop drug } \\
\text { treatment }\end{array}$ & $\begin{array}{l}\text { Permanently stop drug } \\
\text { treatment }\end{array}$ & $\begin{array}{l}\text { Permanently stop drug } \\
\text { treatment }\end{array}$ & $\begin{array}{l}\text { Stop drug until resolved } \\
\text { to } \leq \text { grade } 1 ; \text { consider } \\
\text { restarting drug } \\
\text { treatment at reduced } \\
\text { dosage }\end{array}$ & $\begin{array}{l}\text { Withhold drug treatment and } \\
\text { admit patient to hospital for } \\
\text { psychiatric evaluation }\end{array}$ \\
\hline \multicolumn{6}{|c|}{$\begin{array}{l}\text { Abbreviations: ADL, activities of daily living; CTCAE, Common Terminology } \\
\text { Criteria for Adverse Events; FPG, fasting plasma glucose. }\end{array}$} \\
\hline \multicolumn{6}{|c|}{$\begin{array}{l}\text { SI conversion factor: To convert the serum glucose level to millimoles per liter, } \\
\text { multiply by } 0.0555 \text {. }\end{array}$} \\
\hline
\end{tabular}

venous PI3K Inhibitor BAY80-6946 in Patients With Relapsed, Indolent, or Aggressive Non-Hodgkin's Lymphomas (CHRONOS-1) trial, which led to FDA approval of the drug, showed a grade 3 or 4 transient hyperglycemia in $41 \%$ of patients. ${ }^{14}$ Development of buparlisib has been interrupted because of the high levels of toxic effects and modest antitumor activity. Again, across phases 2 and 3 clinical trials with this agent, all-grade hyperglycemia was reported as one of the most frequent adverse events, with an incidence ranging from $12 \%$ to $58 \%{ }^{28,29}$ Given the frequency of hyperglycemia as an adverse event, patients should be screened for a history of diabetes or insulin resistance before beginning therapy with PI3K inhibitors. Patients who experience hyperglycemia should always be instructed to follow dietary guidelines. This toxic effect is usually manageable with the use of antidiabetic treatment, starting with oral medication. The treatment goals for glycemic control should be a fasting serum glucose level of less than $160 \mathrm{mg} / \mathrm{dL}$ (to convert to millimoles per liter, multiply by 0.0555$)$, random serum glucose level of less than $200 \mathrm{mg} / \mathrm{dL}$, and glycated hemoglobin $\left(\mathrm{HbA}_{\mathrm{cc}}\right)$ level of $8 \%$ or less (to convert to a proportion of 1 , multiply by 0.01 ) to prevent acute and subacute complications of hyperglycemia. ${ }^{30} \mathrm{Gen}$ eral recommendations about management of hyperglycemia induced by PI3K inhibitors are summarized in Table 2.

\section{Cutaneous Reactions}

Cutaneous reactions have been reported in 31 of 146 patients (21.2\%) treated with idelalisib monotherapy; of these, 4 (2.7\%) were grade 3 or higher. ${ }^{31}$ A case of toxic epidermal necrolysis occurred in a study in which idelalisib was combined with bendamustine plus rituximab. ${ }^{32,33}$ Grade 3 cutaneous toxic effects occurred in $2.8 \%$ and grade 4 cutaneous toxic effects occurred in $0.6 \%$ of 317 patients treated with copanlisib monotherapy. ${ }^{11,14,25}$ The most frequent cutaneous toxic effects reported in clinical trials with PI3K inhibitors were maculopapular eruption, pruritus, and dry skin. The onset is typically within the first 2 months of treatment, and it is usually manageable with adequate concomitant medication. Skin reactions tend to fade slowly across 10 days or more. For Common Terminology Criteria for Adverse Events grades 1 and 2 reactions, the recommendation is to monitor the reaction closely. In case of cutaneous toxic effects of grade 3 or higher, treatment interruption and eventual dose reduction is required. Severe cutaneous reactions, such as StevensJohnson syndrome or erythema multiforme, have been described. Consultation with a dermatologist is highly recommended for better assessment and management of PI3K-induced skin toxic effects. Recommended therapies include topical corticosteroids, oral antihistamines, and low-dose oral corticosteroids. If skin lesions are 
still not controlled, topical antibiotics, oral antibiotics (100 mg of doxycycline twice daily; $100 \mathrm{mg}$ of minocycline twice daily), topical antipruritic agents, and $\mathrm{y}$-aminobutyric acid agonists may be considered. Dry skin has commonly been observed; thus, it is recommended that patients use fragrance-free soaps and mild moisturizers (eg, ammonium lactate cream, 12\%). ${ }^{25,34}$

\section{Hypertension}

Some studies demonstrated the expression of PI3KY in endothelial cells and vascular smooth muscle cells. ${ }^{35}$ The isoform PI3KY is involved in blood pressure homeostasis by regulating vascular function and, particularly, myogenic tone through regulation of calcium channels functions via AKT signaling. ${ }^{16,17} \mathrm{PI} 3 \mathrm{~K}$, expressed in vascular smooth muscle cells, has a crucial role in maintaining the balance between vasoconstriction and vasorelaxation induced by $\mathrm{G}$ protein-coupled receptor agonist angiotensin II. ${ }^{26} \mathrm{It}$ is plausible that hypertension is also characterized by immune cells' infiltration in peripheral target organs. ${ }^{36}$ Insulin-dependent vasoconstriction has been suggested as another possible mechanism for PI3K inhibitorassociated hypertension. ${ }^{37}$ Hypertension has been mainly associated with the use of copanlisib. In 2 phase 2 clinical trials of copanlisib, incidence of transient hypertension was reported in $30 \%$ of patients in one of the trials ${ }^{14}$ and $54.8 \%$ of patients in the other trial. ${ }^{11}$ In 2 trials, hypertension of grade 3 or higher was reported respectively in $24 \%{ }^{14}$ and $40.5 \%{ }^{11}$ of patients. According to recommendations from the FDA package insert and prescribing information for copanlisib, optimal blood pressure control (<140/90 mm Hg) should be achieved before starting each infusion of the drug. Blood pressure before and after infusion should be carefully monitored. ${ }^{34} \mathrm{Co}$ panlisib should be withheld for any preinfusion blood pressure of $150 / 90 \mathrm{~mm} \mathrm{Hg}$ or higher until blood pressure is lowered on 2 consecutive measurements at least 15 minutes apart. If the blood pressure after the dose is $150 / 90 \mathrm{~mm} \mathrm{Hg}$ or higher with no evidence of end-organ damage, an antihypertensive treatment may be considered and a dose reduction should be discussed. In case of lifethreatening consequences, severe hypertension, or uncontrolled blood pressure despite optimal treatment, copanlisib therapy should be discontinued.

\section{Pneumonitis}

Pneumonitis, including fatal cases, has occurred in patients treated with drugs targeting the PI3K/AKT/mTOR pathway. Among 146 patients receiving idelalisib monotherapy, pneumonitis was reported in $37(25.2 \%) .{ }^{38}$ Across clinical trials, 24 of 760 patients (3.1\%) treated with idelalisib in monotherapy or combination therapy experienced noninfectious pneumonitis, with a fatal outcome in 3 patients. Results from autopsy revealed findings consistent with hypersensitivity pneumonitis. ${ }^{39,40}$ In a phase 2 study investigating the combination of idelalisib and entospletinib, high rates of autoimmune pneumonitis were reported; in the peripheral blood of affected patients, elevated levels of the helper T cell subtype 1-associated cytokines interferon $y$, interleukin 6 (IL-6), IL-7, and IL-8 were found. ${ }^{41}$ Similarly, noninfectious pneumonitis occurred in 317 patients (5\%) treated with copanlisib monotherapy. ${ }^{11,14,25}$ The mechanisms and management of PI3K inhibitor-induced pneumonitis have not fully been elucidated. However, reports of pneumonitis are consistent with the ones associated with the use of mTOR inhibitors for which guidelines have already been suggested. ${ }^{18}$ The US prescrib- ing information for idelalisib and copanlisib ${ }^{20,38}$ recommends a careful monitoring of respiratory tract symptoms in patients receiving PI3K inhibitors. New-onset cough, dyspnea, hypoxia, interstitial infiltrates on a radiologic examination, or a greater than $5 \%$ decline in oxygen saturation requires an immediate evaluation for pneumonitis and drug interruption until the cause has been determined. The diagnostic workup may include high-resolution computed tomography of the chest and eventual bronchoscopy or bronchoalveolar lavage. Different possible causes of pneumonitis should be considered, including autoimmune pneumonitis, infectious disease, even opportunistic, and patients should be tested for Pneumocystis jirovecii pneumonia and cytomegalovirus infections. Once infectious pneumonia has been ruled out, treatment with corticosteroids could be administered in addition to antibiotics. After diagnosis, management depends on the toxic effect grade and may include interruption of treatment. $34,39,42$

\section{Neuropsychiatric Effects}

Depression, anxiety, and confusion have been observed with PI3K inhibitors, especially with buparlisib. ${ }^{19}$ In the study of Younes et al, ${ }^{15}$ some neuropsychiatric effects were reported in up to one-third of patients, with a grade 3 or higher confusion in up to $10 \%$. The pathogenesis of neuropsychiatric effects is not well understood. However, mood alterations associated with buparlisib treatment may reflect the capacity of this PI3K inhibitor to cross the blood-brain barrier. ${ }^{43}$ In the phase 3 Study of BKM120 With Fulvestrant in Patients With HR+,HER2-, Al Treated, Locally Advanced or Metastatic Breast Cancer Who Progressed on or After mTORi (BELLE 3), ${ }^{28}$ suicidal ideation was reported in 5 of 288 postmenopausal women (1.7\%) randomly assigned to receive buparlisib and fulvestrant, with 3 suicide attempts. Similarly 3 of 573 patients $(0.5 \%)$ enrolled in the Phase 3 Study of BKM120/Placebo With Fulvestrant in Postmenopausal Patients With Hormone Receptor Positive HER2-Negative Locally Advanced or Metastatic Breast Cancer Refractory to Aromatase Inhibitor (BELLE 2) experienced suicidal ideation. ${ }^{44}$ In a systematic review and meta-analysis, the addition of PI3K inhibitors resulted in a significant increased risk of depression (odds ratio [OR], 9.72; 95\% Cl, 2.67-35.35) and anxiety (OR, 5.84; 95\% Cl, $2.39-14.28)^{45}$; overall, grade 3 or higher depression occurred in 30 of 1571 patients (1.9\%); with an incidence of $3.3 \%$ in patients treated with PI3K inhibitors plus endocrine therapy compared with $0.3 \%$ in the endocrine therapy alone arm. To improve awareness among cancer care practitioners, the American Society of Clinical Oncology released a guideline adaptation on screening, assessment, and care of depressive symptoms and anxiety in patients with cancer. ${ }^{46}$ Care should be taken in screening all patients for psychiatric history, with particular consideration given to any history of depression or bipolar disorder at baseline. In patients with mood or neuropsychiatric symptoms higher than grade 2, PI3K inhibitors should be withheld and a psychiatric evaluation should be performed. Suicidal ideation or homicidal ideation should prompt immediate psychiatric evaluation.

\section{Hepatotoxic Effects}

Severe autoimmune transaminitis has been described with idelalisib use; also copanlisib and buparlisib treatment have been correlated with hepatotoxic effects, although generally of lesser severity. Elevations in alanine aminotransferase (ALT) or aspartate 
aminotransferase (AST) more than 5 times the upper limit of the normal range have been observed within the first 12 weeks of treatment. ${ }^{25,38}$ Most transaminase elevations were reversible with dose interruption for idelalisib-treated patients. ${ }^{38}$ Across idelalisib clinical trials, serious adverse events of transaminitis treatment were reported in 109 of 760 patients (14.3\%), with 1 death (1 of 1192 $[0.08 \%]$ ) in a patient who received idelalisib in combination with ofatumumab in an ongoing phase 3 clinical trial. ${ }^{38}$ Most patients (73.9\%) with increased ALT and AST levels restarted idelalisib treatment at a lower dose without recurrence; however, 198 of 760 (26.0\%) had a recurrence of elevated ALT and AST levels despite the lower dose. ${ }^{38}$ Among 24 patients with relapsed or refractory chronic lymphocytic leukemia treated with idelalisib, 19 (79\%) experienced a transaminase level elevation. Previously untreated disease and younger age were shown to be associated with an increased risk of autoimmune toxic effects. ${ }^{47}$ Patients experiencing hepatotoxic effects had significantly higher levels of the proinflammatory cytokines CCL-3 and CCL-4. Liver biopsy specimens from these patients showed an increased infiltrate of $C D 8^{+}$cytotoxic T cells. In a phase 3 clinical trial, 110 patients with chronic lymphocytic leukemia were treated with idelalisib plus rituximab, and hepatotoxic effects were one of the most common adverse effects that led to idelalisib dose reduction and treatment discontinuation. ${ }^{48}$ In the BELLE 2 trial ${ }^{44}$ and BELLE 3 trial, ${ }^{28}$ patients treated with buparlisib experienced grade 3 or 4 of transaminitis in up to $25 \%$ and $20 \%$ of the cases, respectively. The phase 2 Neoadjuvant Trastuzumab + BKM12O in Combination With Weekly Paclitaxel in HER2-Positive Primary Breast Cancer (NeoPHOEBE) neoadjuvant study was designed to evaluate the combination of buparlisib with trastuzumab and paclitaxel in patients with HER2-positive breast cancer; after enrollment of the first 50 patients, recruitment was stopped because of hepatotoxic effects. ${ }^{49}$ The expert panel recommends monitoring ALT and AST concentrations every 2 weeks for the first 3 months of treatment, followed by a monthly assessment for the next 3 months and every 1 to 3 months thereafter. The frequency of monitoring should be weekly in any instance of ALT or AST concentrations greater than 3 times the upper limit of the reference range until resolved. If the transaminase level elevation is 3 to 5 times the upper limit of the reference range, idelalisib treatment can be continued at its current dosage, but ALT and AST levels must be monitored weekly until normalization. If the ALT or AST level is more than 5 times the upper limit of the reference range, idelalisib treatment should be withheld and eventually restarted at a reduced dosage once all liver function test results normalize. Patients who experience severe transaminitis (ie, values $>20$ times the upper limit of the reference range) should permanently discontinue therapy. A similar approach is recommended for hepatotoxic effects associated with the use of other PI3K inhibitors. ${ }^{34}$

\section{Diarrhea and Colitis}

Immune-mediated colitis from PI3K inhibitors manifests initially as nonbloody and watery diarrhea that does not respond to antimotility agents. In some studies, colonic biopsy specimens of patients experiencing idelalisib-related diarrhea revealed neutrophilic infil- tration, intraepithelial lymphocytosis, and crypt cell apoptosis. ${ }^{50-52}$ Across clinical trials with idelalisib, $14 \%$ to $19 \%$ of patients experienced grade 3 or 4 diarrhea and colitis. ${ }^{38}$ Intestinal perforation occurred in 6 of 1192 patients ( $0.5 \%$ ) treated across phases 1, 2, and 3 trials. ${ }^{39}$ Diarrhea can be divided into 2 groups: the first is typically self-limited, responds well to antimotility agents, and occurs within the first 8 weeks of initiation of therapy (median [range], 1.9 [0.029.8] months). The second type occurs at a median [range] time of 7.1 [0.0-15.2] months after start of treatment and responds poorly to antimotility agents. ${ }^{39}$ Across several clinical trials, there were 106 cases of grade 3 or higher colitis requiring interruption of therapy. Diarrhea during treatment with PI3K inhibitors should prompt evaluation for other causes-including dietary factors, infection, and medications-followed by diagnostic testing with Clostridium difficile testing, stool culture, and colonoscopy for atypical or refractory cases. PI3K inhibitor therapy should be immediately interrupted in patients experiencing unresolved grade 2 or any episodes of grade 3 or higher diarrhea after exclusion of infectious diarrhea; the diarrhea should be treated with budesonide, $9 \mathrm{mg}$ daily, or prednisolone, $1 \mathrm{mg} / \mathrm{kg}$ daily, until symptoms diminish to grade 1 or lower. ${ }^{39}$

\section{Conclusions}

In recent years, only idelalisib and copanlisib have been approved by the FDA for clinical use in the treatment of patients with hematologic cancers. ${ }^{14,39,48,53,54}$ Overall, the clinical development of most $\mathrm{PI} 3 \mathrm{~K}$ inhibitors has been discontinued owing to insufficient activity, problematic toxic effects, and the absence of biomarkers correlated with clinical activity. Knowledge of the isoforms and their distribution in tissue can help clinicians anticipate toxic effects. Notably, novel, more specific inhibitors for individual isoforms of PI3K showed therapeutic activity with improved toxic effect profiles compared with non-isoform-selective agents. ${ }^{55}$ Alpelisib is the first PI3Ka inhibitor to demonstrate clinical progression-free survival improvements in metastatic hormone receptor-positive, HER2-negative breast cancer with activating PIK3CA mutations. These results suggest that isoform-specific PI3K inhibitors display greater clinical activity and a more favorable safety profile. ${ }^{9}$ In addition, in this trial, life-threatening toxic effects or major toxic effects that would be expected to affect the quality of life of patients were not reported. If approved, alpelisib will necessitate testing patients for PIK3CA mutations in routine practice-a major change in the current diagnostic workup for breast cancer. For example, alpelisib has recently shown activity in 19 patients affected by CLOVES syndrome (congenital lipomatous overgrowth, vascular malformations, epidermal nevi, scoliosis, and skeletal and spinal syndrome), a genetic disorder resulting from somatic, mosaic gain-of-function mutations of the PIK3CA gene. ${ }^{56}$ The next step in the clinical development of PI3K inhibitors might be focused on the exploration of new dosage schedules, the investigation of combinations that overcome PI3K resistance, and the identification of predictive biomarkers of clinical activity. The identification of tumors harboring specific PI3K pathway alterations may lead to a more personalized treatment.
ARTICLE INFORMATION

Accepted for Publication: December 12, 2018.
Published Online: March 28, 2019. doi:10.1001/jamaoncol.2019.0034
Author Contributions: Drs Curigliano and Esposito had full access to all of the data in the study and 
take responsibility for the integrity of the data and the accuracy of the data analysis.

Concept and design: All authors.

Acquisition, analysis, or interpretation of data: Viale,

Curigliano.

Drafting of the manuscript: All authors.

Critical revision of the manuscript for important intellectual content: Curigliano.

Administrative, technical, or material support: Viale, Curigliano.

Supervision: Esposito, Curigliano.

Conflict of Interest Disclosures: Dr Curigliano reported receiving personal fees from Novartis Pfizer, and Roche for expert presentations and personal fees as a member of the advisory board for Ellipses Pharma, Foundation Medicine, Lilly, Novartis, Pfizer, Roche, Samsung, and Seattle Genetics. No other disclosures were reported.

\section{REFERENCES}

1. Janku F, Yap TA, Meric-Bernstam F. Targeting the PI3K pathway in cancer: are we making headway? Nat Rev Clin Oncol. 2018;15(5):273-291. doi:10 1038/nrclinonc.2018.28

2. Sarbassov DD, Guertin DA, Ali SM, Sabatini DM. Phosphorylation and regulation of Akt/PKB by the rictor-mTOR complex. Science. 2005;307(5712): 1098-1101. doi:10.1126/science.1106148

3. Fekete M, Santiskulvong C, Eng C, Dorigo O. Effect of PI3K/Akt pathway inhibition-mediated G1 arrest on chemosensitization in ovarian cancer cells. Anticancer Res. 2012;32(2):445-452.

4. Janku F, Tsimberidou AM, Garrido-Laguna I, et al. PIK3CA mutations in patients with advanced cancers treated with PI3K/AKT/mTOR axis inhibitors. Mol Cancer Ther. 2011;10(3):558-565. doi:10.1158/1535-7163.MCT-10-0994

5. Carnero A, Blanco-Aparicio C, Renner O, Link W, Leal JF. The PTEN/PI3K/AKT signalling pathway in cancer, therapeutic implications. Curr Cancer Drug Targets. 2008;8(3):187-198. doi:10.2174/ 156800908784293659

6. Vanhaesebroeck B, Guillermet-Guibert J, Graupera M, Bilanges B. The emerging mechanisms of isoform-specific PI3K signalling. Nat Rev Mol Cell Biol. 2010;11(5):329-341. doi:10.1038/nrm2882

7. Liu P, Cheng H, Roberts TM, Zhao JJ. Targeting the phosphoinositide 3-kinase pathway in cancer. Nat Rev Drug Discov. 2009;8(8):627-644. doi:10. 1038/nrd2926

8. LoRusso PM. Inhibition of the PI3K/AKT/mTOR Pathway in Solid Tumors. J Clin Oncol. 2016;34(31): 3803-3815. doi:10.1200/JCO.2014.59.0018

9. Andre F, Ciruelos EM, Rubovszky G, et al. Alpelisib + fulvestrant for HR+, HER2-advanced breast cancer: results of the phase III SOLAR-1 trial [abstract LBA3_PR]. Presented at: European Society for Medical Oncology (ESMO) Congress; October 20, 2018; Munich, Germany.

10. Baselga J, Dent SF, Cortés J, et al. Phase III study of taselisib (GDC-0032) + fulvestrant (FULV) $\checkmark$ FULV in patients (pts) with estrogen receptor (ER)-positive, PIK3CA-mutant (MUT), locally advanced or metastatic breast cancer (MBC): primary analysis from SANDPIPER [abstract LBA1006]. In: Proceedings of the American Society of Clinical Oncology; June 1-5, 2018; Chicago, IL. Alexandria, VA: American Society of Clinical Oncology; 2018.
11. Dreyling M, Morschhauser F, Bouabdallah $K$, et al. Phase II study of copanlisib, a PI3K inhibitor, in relapsed or refractory, indolent or aggressive lymphoma. Ann Oncol. 2017;28(9):2169-2178. doi: 10.1093/annonc/mdx289

12. Juric D, Rodon J, Tabernero J, et al. Phosphatidylinositol 3-kinase a-selective inhibition with alpelisib (BYL719) in PIK3CA-altered solid rumors: results from the first-in-human study. J Clin Oncol. 2018;36(13):1291-1299. doi:10.1200/JCO. 2017.72.7107

13. Mayer IA, Abramson VG, Formisano L, et al. A phase lb study of alpelisib (BYL719), a $\mathrm{PI3Ka-specific} \mathrm{inhibitor,} \mathrm{with} \mathrm{letrozole} \mathrm{in}$ ER+/HER2- metastatic breast cancer. Clin Cancer Res. 2017;23(1):26-34. doi:10.1158/1078-0432.CCR-160134

14. Dreyling M, Santoro A, Mollica L, et al. Phosphatidylinositol 3-kinase inhibition by copanlisib in relapsed or refractory indolent lymphoma. J Clin Oncol. 2017;35(35):3898-3905. doi:10.1200/JCO.2017.75.4648

15. Younes A, Salles G, Bociek RG, et al. An open-label phase II study of buparlisib (BKM120) in patients with relapsed and refractory diffuse large B-cell lymphoma, mantle cell lymphoma or follicular lymphoma. Blood. 2014;124(21):1718.

16. Carnevale D, Lembo G. PI3Kץ in hypertension: a novel therapeutic target controlling vascular myogenic tone and target organ damage.

Cardiovasc Res. 2012;95(4):403-408. doi:10.1093/ cvr/cvs166

17. Le Blanc C, Mironneau C, Barbot C, et al. Regulation of vascular L-type Ca2+ channels by phosphatidylinositol 3,4,5-trisphosphate. Circ Res. 2004:95(3):300-307. doi:10.1161/01.RES 0000138017.76125.8b

18. Duran I, Goebell PJ, Papazisis K, et al. Drug-induced pneumonitis in cancer patients treated with mTOR inhibitors: management and insights into possible mechanisms. Expert Opin Drug Saf. 2014;13(3):361-372. doi:10.1517/14740338. 2014.888056

19. Maira SM, Pecchi S, Huang A, et al. Identification and characterization of NVP-BKM12O, an orally available pan-class I PI3-kinase inhibitor. Mol Cancer Ther. 2012;11(2):317-328. doi:10.1158/ 1535-7163.MCT-11-0474

20. de Weerdt I, Koopmans SM, Kater AP, van Gelder M. Incidence and management of toxicity associated with ibrutinib and idelalisib: a practical approach. Haematologica. 2017;102(10):1629-1639. doi:10.3324/haematol.2017.164103

21. Engelman JA. Targeting PI3K signalling in cancer: opportunities, challenges and limitations. Nat Rev Cancer. 2009;9(8):550-562. doi:10.1038/ nrc2664

22. Pauls SD, Lafarge ST, Landego I, Zhang T, Marshall AJ. The phosphoinositide 3-kinase signaling pathway in normal and malignant B cells: activation mechanisms, regulation and impact on cellular functions. Front Immunol. 2012;3:224. doi: 10.3389/fimmu.2012.00224

23. Okkenhaug K. Two birds with one stone: dual p110ס and p110y inhibition. Chem Biol. 2013;20(11) 1309-1310. doi:10.1016/j.chembiol.2013.11.002

24. Awada $\mathrm{AH}$, Morschhauser $\mathrm{F}$, Machiels J, et al $\mathrm{PI} 3 \mathrm{~K}$ inhibition and modulation of immune and tumor microenvironment markers by copanlisib in patients with non-Hodgkin's lymphoma or advanced solid tumours [abstract 67P]. Ann Oncol. 2018;29(suppl 8):viii14-viii57. doi:10.1093/annonc/ mdy269.065

25. Aliqopa (copanlisib) injection [draft of package insert]. Whippany, NJ: Bayer HealthCare Pharmaceuticals Inc; 2017.

26. Vecchione $C$, Patrucco E, Marino G, et al. Protection from angiotensin II-mediated vasculotoxic and hypertensive response in mice lacking PI3Kgamma. J Exp Med. 2005;201(8):12171228. doi:10.1084/jem.20040995

27. Jain S, Shah AN, Santa-Maria CA, et al. Phase I study of alpelisib (BYL-719) and trastuzumab emtansine (T-DM1) in HER2-positive metastatic breast cancer (MBC) after trastuzumab and taxane therapy. Breast Cancer Res Treat. 2018;171(2):371-381. doi:10.1007/s10549-018-4792-0

28. Di Leo A, Johnston S, Lee KS, et al. Buparlisib plus fulvestrant in postmenopausal women with hormone-receptor-positive, HER2-negative, advanced breast cancer progressing on or after mTOR inhibition (BELLE-3): a randomised, double-blind, placebo-controlled, phase 3 trial. Lancet Oncol. 2018;19(1):87-100. doi:10.1016/ S1470-2045(17)30688-5

29. Heudel PE, Fabbro M, Roemer-Becuwe C, et al. Phase II study of the PI3K inhibitor BKM12O in patients with advanced or recurrent endometrial carcinoma: a stratified type I-type II study from the GINECO group. Br J Cancer. 2017;116(3):303-309. doi:10.1038/bjc.2016.430

30. Busaidy NL, Farooki A, Dowlati A, et al. Management of metabolic effects associated with anticancer agents targeting the PI3K-Akt-mTOR pathway. J Clin Oncol. 2012;30(23):2919-2928. doi: 10.1200/JCO.2011.39.7356

31. Miller BW, Przepiorka D, de Claro RA, et al. FDA approval: idelalisib monotherapy for the treatment of patients with follicular lymphoma and small lymphocytic lymphoma. Clin Cancer Res. 2015;21 (7):1525-1529. doi:10.1158/1078-0432.CCR-14-2522

32. Zelenetz AD, Barrientos JC, Brown JR, et al. Idelalisib or placebo in combination with bendamustine and rituximab in patients with relapsed or refractory chronic lymphocytic leukaemia: interim results from a phase 3 . randomised, double-blind, placebo-controlled trial. Lancet Oncol. 2017;18(3):297-311. doi:10.1016/ S1470-2045(16)30671-4

33. de Vos S, Wagner-Johnston ND, Coutre SE, et al. Combinations of idelalisib with rituximab and/or bendamustine in patients with recurrent indolent non-Hodgkin lymphoma. Blood Adv. 2016; 1(2):122-131. doi:10.1182/bloodadvances.2016000976

34. Greenwell IB, Ip A, Cohen JB. PI3K inhibitors: understanding toxicity mechanisms and management. Oncology (Williston Park). 2017;31(11) 821-828.

35. Morello F, Perino A, Hirsch E. Phosphoinositide 3-kinase signalling in the vascular system. Cardiovasc Res. 2009;82(2):261-271. doi:10.1093/ cvr/cvn325

36. Carnevale D, Pallante F, Fardella V, et al. The angiogenic factor PIGF mediates a neuroimmune interaction in the spleen to allow the onset of hypertension. Immunity. 2014;41(5):737-752. doi: 10.1016/j.immuni.2014.11.002 
37. Symons JD, McMillin SL, Riehle C, et al. Contribution of insulin and Akt1 signaling to endothelial nitric oxide synthase in the regulation of endothelial function and blood pressure. Circ Res. 2009;104(9):1085-1094. doi:10.1161/CIRCRESAHA. 108.189316

38. Zydelig (idelalisib tablets) [package insert]. Foster City, CA: Gilead Sciences, Inc; 2014.

39. Coutré SE, Barrientos JC, Brown JR, et al. Management of adverse events associated with idelalisib treatment: expert panel opinion. Leuk Lymphoma. 2015;56(10):2779-2786. doi:10.3109/ 10428194.2015.1022770

40. Gopal AK, Kahl BS, de Vos S, et al. PI3Kס inhibition by idelalisib in patients with relapsed indolent lymphoma. N Engl J Med. 2014;370(11): 1008-1018. doi:10.1056/NEJMoa1314583

41. Barr PM, Saylors GB, Spurgeon SE, et al. Phase 2 study of idelalisib and entospletinib: pneumonitis limits combination therapy in relapsed refractory CLL and NHL. Blood. 2016;127(20):2411-2415. doi: 10.1182/blood-2015-12-683516

42. Haustraete E, Obert J, Diab S, et al. Idelalisib-related pneumonitis. Eur Respir J. 2016;47 (4):1280-1283. doi:10.1183/13993003.01670-2015

43. Bendell JC, Rodon J, Burris HA, et al. Phase I, dose-escalation study of BKM12O, an oral pan-class I PI3K inhibitor, in patients with advanced solid tumors. J Clin Oncol. 2012;30(3):282-290. doi:10. 1200/JCO.2011.36.1360

44. Baselga J, Im SA, Iwata $H$, et al. Buparlisib plus fulvestrant versus placebo plus fulvestrant in postmenopausal, hormone receptor-positive, HER2-negative, advanced breast cancer (BELLE-2): a randomised, double-blind, placebo-controlled, phase 3 trial. Lancet Oncol. 2017;18(7):904-916. doi:10.1016/S1470-2045(17)30376-5

45. Martel S, Bruzzone M, Ceppi M, et al. Risk of adverse events with the addition of targeted agents to endocrine therapy in patients with hormone receptor-positive metastatic breast cancer: a systematic review and meta-analysis. Cancer Treat Rev. 2018;62:123-132. doi:10.1016/j.ctrv.2017.09.009

46. Andersen BL, DeRubeis RJ, Berman BS, et al; American Society of Clinical Oncology. Screening, assessment, and care of anxiety and depressive symptoms in adults with cancer: an American Society of Clinical Oncology guideline adaptation. J Clin Oncol. 2014;32(15):1605-1619. doi:10.1200/ JCO.2013.52.4611

47. Lampson BL, Kasar SN, Matos TR, et al. Idelalisib given front-line for treatment of chronic lymphocytic leukemia causes frequent immune-mediated hepatotoxicity. Blood. 2016;128 (2):195-203. doi:10.1182/blood-2016-03-707133

48. Furman RR, Sharman JP, Coutre SE, et al. Idelalisib and rituximab in relapsed chronic lymphocytic leukemia. N Engl J Med. 2014;370(11): 997-1007. doi:10.1056/NEJMoa1315226

49. Loibl S, de la Pena L, Nekljudova V, et al. Neoadjuvant buparlisib plus trastuzumab and paclitaxel for women with HER2 + primary breast cancer: a randomised, double-blind, placebo-controlled phase II trial (NeoPHOEBE). Eur J Cancer. 2017;85:133-145. doi:10.1016/j.ejca.2017. 08.020

50. O'Brien SM, Lamanna N, Kipps TJ, et al. A phase 2 study of idelalisib plus rituximab in treatment-naïve older patients with chronic lymphocytic leukemia. Blood. 2015;126(25):26862694. doi:10.1182/blood-2015-03-630947

51. Weidner AS, Panarelli NC, Geyer JT, et al. Idelalisib-associated colitis: histologic findings in 14 patients. Am J Surg Pathol. 2015;39(12):1661-1667. doi:10.1097/PAS.0000000000000522

52. Louie CY, DiMaio MA, Matsukuma KE, Coutre SE, Berry GJ, Longacre TA. Idelalisib-associated enterocolitis: clinicopathologic features and distinction from other enterocolitides. Am J Surg Pathol. 2015;39(12):1653-1660. doi:10.1097/PAS. 0000000000000525

53. de Vos S, Wagner-Johnston ND, Coutre SE, et al. Combinations of idelalisib with rituximab and/or bendamustine in patients with recurrent indolent non-Hodgkin lymphoma. Blood Adv. 2016; 1(2):122-131. doi:10.1182/bloodadvances.2016000976

54. Greenwell IB, Flowers CR, Blum KA, Cohen JB. Clinical use of PI3K inhibitors in B-cell lymphoid malignancies: today and tomorrow. Expert Rev Anticancer Ther. 2017;17(3):271-279. doi:10.1080/ 14737140.2017.1285702

55. Rodon J, Dienstmann R, Serra V, Tabernero J. Development of PI3K inhibitors: lessons learned from early clinical trials. Nat Rev Clin Oncol. 2013;10 (3):143-153. doi:10.1038/nrclinonc.2013.10

56. Venot Q, Blanc T, Rabia SH, et al. Targeted therapy in patients with PIK3CA-related overgrowth syndrome. Nature. 2018;558(7711): 540-546. doi:10.1038/s41586-018-0217-9 